\title{
A case report of primary small cell carcinoma of the breast and review of the literature
}

\author{
Qi-Dong Ge $e^{1,2}$, Ning Lv' ${ }^{1,2}$, Yun Cao ${ }^{1,3}$, Xi Wang ${ }^{1,2}$, Jun Tang ${ }^{1,2}$, Ze-Ming Xie ${ }^{1,2}$, \\ Xiang-Sheng Xiao, ${ }^{1,2}$, Peng Liu' ${ }^{1,2}$, Xiao-Ming Xie ${ }^{1,2}$ and Wei-Dong Wei ${ }^{1,2}$
}

\begin{abstract}
Primary small cell carcinoma (SCC) of the breast, an exceedingly rare and aggressive tumor, is often characterized by rapid progression and poor prognosis. We report a case of primary SCC of the breast that was diagnosed through pathologic and immunohistochemical examinations. Computed tomography (CT) scans failed to reveal a non-mammary primary site. Due to the scant number of relevant case summaries, this type of tumor is proved to be a diagnostic and therapeutic challenge. Therefore, we also reviewed relevant literature to share expertise in diagnosis, clinicopathologic characteristics, treatment, and prognosis of this type of tumor. Future studies with more cases are required to define more appropriate treatment indications for this disease.
\end{abstract}

Key words: Small cell carcinoma, breast, neuroendocrine

Primary small cell carcinoma (SCC) of the breast is a subtype of neuroendocrine carcinoma. Wade et al. ${ }^{[1]}$ described the first case of SCC of the breast in 1983. To our knowledge, there are less than 60 reported cases in the literature. The diagnosis of this disease can only be made if there is no evidence for a non-mammary site or if an in situ component can be demonstrated ${ }^{[2]}$. Primary SCC of the breast accounts for less than $1 \%$ of primary breast cancers ${ }^{[3]}$. Due to the rarity of this type of tumor and the lack of a standard treatment, we report here a case of primary SCC of the breast and discuss its clinicopathologic characteristics with literature review.

\section{Case Report}

In October 2011, a 39-year-old woman presented a painless mass in her left breast for 3 months. There

\footnotetext{
Authors' Affiliations: 'State Key Laboratory of Oncology in South China Guangzhou, Guangdong 510060, P. R. China; ${ }^{2}$ Department of Breast Oncology, ${ }^{3}$ Department of Pathology, Sun Yat-sen University Cancer Center, Guangzhou, Guangdong 510060, P. R. China.

Corresponding Author: Wei-Dong Wei, Department of Breast Oncology, Sun Yat-sen University Cancer Center, Guangzhou, Guangdong 510060, P. R. China. Tel: +86-13822278328; Email: weiweid@mail.sysu.edu.cn. doi: $10.5732 /$ cjc. 012.10012
}

were no accompanying symptoms such as nipple retraction, dimpling, or palpable axillary lymph nodes. Physical examination revealed a $2 \mathrm{~cm} \times 2 \mathrm{~cm}$, elastic, firm, ill-defined suspicious mass in the upper outer quadrant of her left breast. On the mammography, the mass appeared round with indistinct margins with lots of punctates and scattered calcifications along the duct (Figure 1A).

Additionally, an ultrasound scan revealed two solid and low heterogeneous echoes in the left breast: one was in the 3 o'clock position, $35 \mathrm{~mm}$ away from the nipple (Figure 1B); the other was also in the 3 o' clock position, $65 \mathrm{~mm}$ away from the nipple (Figure 1C). Both were poorly defined with irregular borders. However, the levels of serum tumor markers, including carcinoembryonic antigen (CEA), carbohydrate antigen 125 (CA125), CA15-3, and CA19-9 were all within normal limits.

The patient did not undergo a fine needle biopsy. An intraoperative biopsy confirmed the pathologic diagnosis of SCC with the component of ductal carcinoma in situ (DCIS). As a result, she underwent modified radical mastectomy with axillary lymph node dissection. Microscopically, the mass (in the 3 o' clock position, 35 $\mathrm{mm}$ away from the nipple) was about $0.8 \mathrm{~cm} \times 0.5 \mathrm{~cm} \times$ $0.5 \mathrm{~cm}$, which was diagnosed histologically as an intermediate grade DCIS, whereas the second mass (in the 3 o' clock position, $65 \mathrm{~mm}$ away from the nipple) was about $1.4 \mathrm{~cm} \times 1.2 \mathrm{~cm} \times 0.6 \mathrm{~cm}$ and was comprised 


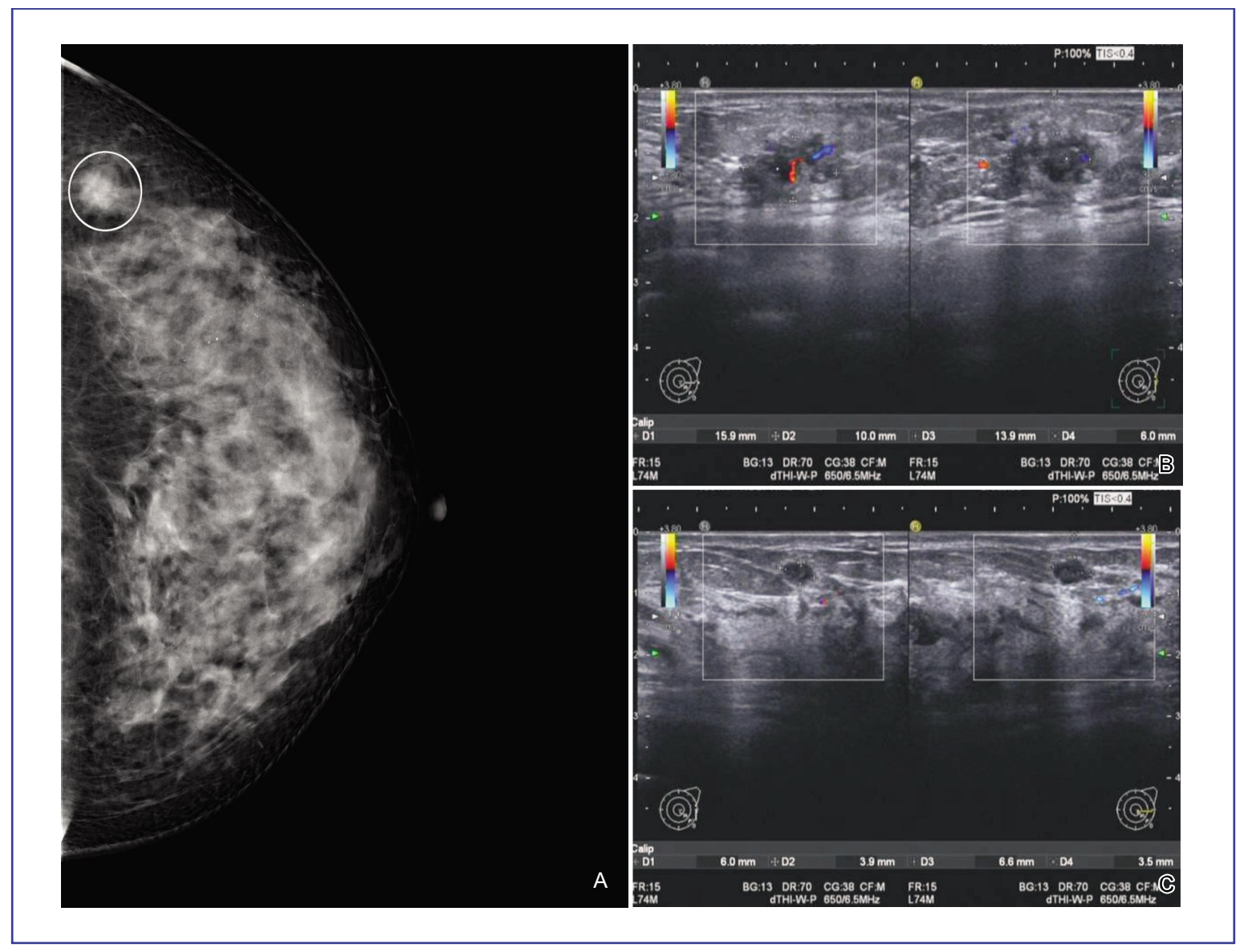

Figure 1. Imaglng examlnatlons of a 39-year-old woman with prlmary small cell carclnoma (SCC) of the breast. A, mammography reveals a round mass with obscure margins and lots of punctates and scattered calcifications along the duct. B and C, ultrasound scan shows two solid and low heterogeneous echoes in the left breast. One is in the 30 'clock position, $65 \mathrm{~mm}$ away from the nipple (B); the other is also in the $30^{\prime}$ 'clock position, $35 \mathrm{~mm}$ away from the nipple (C). Two lesions are both poorly defined with irregular borders.

of intermediate grade DCIS (30\%) and $\operatorname{SCC}(70 \%)$. Histological examination showed that the tumor was composed of small round or oval cells with a high nucleocytoplasmic ratio, small hyperchromatic nuclei, inconspicuous nucleoli, and scant cytoplasm, which were arranged diffusely and patchily. Widespread necrosis was present (Figure 2A). Immunohistochemically, tumor cells of the DCIS component were positive for estrogen receptor (ER), progesterone receptor $(P R)$, and human epidermal growth factor receptor 2 (HER2). However, the tumor cells of the SCC component were negative for these markers, whereas the Ki67 proliferation index (percentage of Ki67-positive cancer nuclei) was $70 \%$. Furthermore, the SCC tumor cells were highly positive for neuroendocrine differentiation markers including synaptophysin (Figure 2B), neuron specific enolase (NSE) (Figure 2C), thyroid transcription factor-1 (TTF1)
(Figure 2D), and CD56 (Figure 2E), but they were negative for chromogranin $A(\mathrm{CgA})$ (Figure 2F). Histological examination also demonstrated 1 positive lymph node out of 13 level I axillary lymph nodes.

Therefore, a search for a non-mammary primary site was carried out, especially focusing on pathologic changes in the lungs. The result of computed tomography (CT) scans of the neck, chest, and upper abdomen were all within normal limits, and bone scintigraphy was negative for metastatic disease. As a result, we concluded that the breast was the primary site, and primary SCC of the breast was diagnosed.

The patient was treated with six cycles of docetaxel $\left(75 \mathrm{mg} / \mathrm{m}^{2}\right)$ and carboplatin $\left(350 \mathrm{mg} / \mathrm{m}^{2}\right)$ in combination once every three weeks. After the initial treatment, the patient was clinically monitored for disease relapse and metastasis. 


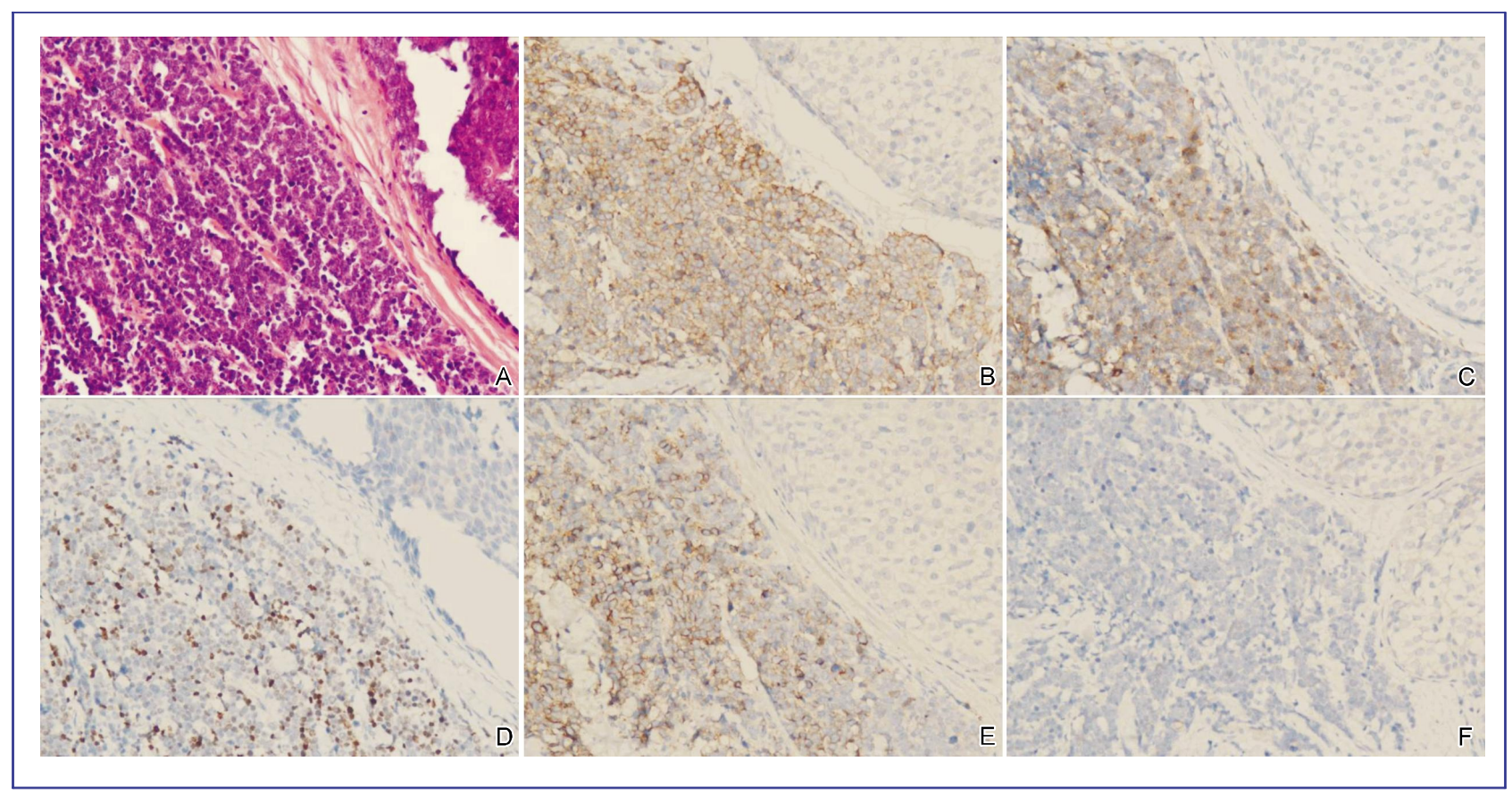

Figure 2. Histological findings of our case study. A, The small cell carcinoma component (left) is comprised of small round or oval cells with hyperchromatic nuclei, scant cytoplasm, and inconspicuous nucleoli, accompanied with a ductal carcinoma in situ component (right) (HE $\times 200)$. $\mathrm{B}-\mathrm{F}$, immunohistochemical staining of the tumor. The small cell carcinoma component (left) is positive for synaptophysin (B), neuron specific enolase (C), thyroid transcription factor-1 $(\mathrm{D})$, and CD56 $(\mathrm{E})$ and is negative for chromogranin $A(F)$; whereas the ductal carcinoma in situ component (right) is negative for all the above markers $(\mathrm{IHC} \times 200)$.

\section{Discussion}

Small cell neuroendocrine carcinoma has been described in many extra-pulmonary sites, including the breast, larynx, gastrointestinal tract, prostate, bladder, ovary, and cervix ${ }^{[4,5]}$. In particular, primary SCC of the breast is considerably rare. To our knowledge, 56 cases have been reported in the literature ${ }^{[1-2,6-38]}$. In summarizing the clinicopathologic characteristics of these cases, most of them are found in women; only two male cases have been reported ${ }^{[6,26]}$. The median age of the patients at presentation was 52 years (range, 29 to 81 years). Tumor size ranged from 1 to $18 \mathrm{~cm}$ (mean, $4.63 \mathrm{~cm}$ ), and about $62.8 \%$ of the tumors (2 to $5 \mathrm{~cm}$ in size) were in T2 stage according to the National Comprehensive Cancer Network (NCCN) guidelines. Approximately $60.4 \%(32 / 53)$ of the patients exhibited axillary lymph node metastasis. Most of them were accompanied by vascular invasion and intraductal lesion. Primary SCC of the breast can be diagnosed if there is no evidence for an extra-mammary primary site or if an in situ component can be demonstrated histopathologically within the breast. It is important that the DCIS component is truly a precursor lesion of SCC and supports a primary breast origin ${ }^{[15]}$. The presence of an in situ component is useful, though not indispensable, toward the diagnosis of primary breast tumors.

We also reviewed previous immunohistochemical reports $^{[1-2,6-38]}$. The tumor cells from approximately $28.8 \%$ $(15 / 52)$ of reported patients were positive for either ER or PR. However, HER2 overexpression has never been reported in these cases. In general, the positive rates of ER, PR, and HER2 were about $60 \%-70 \%, 50 \%-60 \%$, and $20 \%-30 \%$, respectively, displaying a common phenotype of invasive ductal carcinoma ${ }^{[39,40]}$. Moreover, positive neuroendocrine markers could provide strong support for diagnosis. The positive rates of NSE and synaptophysin were $88.2 \%(45 / 51)$ and $63.8 \%$ (30/47), respectively, and some of the tumor cells were positive for CD56, TTF1, CgA, and other markers.

This type of breast carcinoma is rare and has generally been considered to be extremely aggressive. As a result, no standard treatment for this disease exists ${ }^{[1721]}$. The most effective option seems to be modified radical mastectomy with axillary lymph node dissection followed by adjuvant chemotherapy. Considering that the biological characteristics of this type of breast carcinoma are similar to SCC of the lung, effective drugs for SCC, such as platinum compounds and etoposide, were selected to treat these patients; drugs for common types 
of breast cancer were not selected. Paclitaxel has been found safe and effective as first-line therapy for small cell lung carcinoma ${ }^{[41]}$. In addition, paclitaxel-containing regimens have also been used for patients with breast cancer as a standard adjuvant therapy. In the case of SCC with a DCIS component, we prefer a docetaxel and carboplatin combination rather than other ordinary regimens such as cyclophosphamide, epirubicin, and 5-fluorouracil (CEF). Individual treatment strategy, including chemotherapy, radiotherapy, and endocrine therapy alone or in combination, should be determined according to patient's age, tumor size, axillary lymph node status, and molecular phenotype.

The prognosis for this type of tumor is generally believed to be as poor as its pulmonary counterparts ${ }^{[17]}$. However, previous reports show that the prognosis can be better if such tumors are detected at an earlier stage. According to previous reports ${ }^{[1-2,6-38]}$, the mean follow-up time was 21 months (range, 3 to 60 months), the metastasis or relapse rate was $35.7 \% \quad(20 / 56)$, and the mortality was $19.6 \%(11 / 56)$. The most common sites of metastasis were the liver, brain, bone, lungs, and lymph nodes. The treatment of disease relapse, however, remains poorly characterized. As for our 39-year-old

\section{References}

[1] Wade PM Jr, Mills SE, Read M, et al. Small cell neuroendocrine (oat cell) carcinoma of the breast. Cancer, 1983,52:121-125

[2] Papotti M, Gherardi G, Eusebi V, et al. Primary oat cell (neuroendocrine) carcinoma of the breast. Report of four cases. Virchows Arch A Pathol Anat Histopathol, 1992,420: 103-108.

[3] Sapino A, Papotti M, Righi L, et al. Clinical significance of neuroendocrine carcinoma of the breast. Ann Oncol, 2001,12 suppl 2:115-117.

[4] Ibrahim NB, Briggs JC, Corbishley CM. Extrapulmonary oat cell carcinoma. Cancer, 1984,54:1645-1661.

[5] Richardson RL, Weiland LH. Undifferentiated small cell carcinomas in extrapulmonary sites. Semin Oncol, 1982,9:484496

[6] Jundt G, Schulz A, Heitz PU, et al. Small cell neuroendocrine (oat cell) carcinoma of the male breast. Immunocytochemical and ultrastructural investigations. Virchows Arch A Pathol Anat Histopathol, 1984,404:213-221.

[7] Francois A, Chatikhine VA, Chevallier B, et al. Neuroendocrine primary small cell carcinoma of the breast. Report of a case and review of the literature. Am J Clin Oncol, 1995,18:133138

[8] Chua RS, Torno RB, Vuletin JC. Fine needle aspiration cytology of small cell neuroendocrine carcinoma of the breast. A case report. Acta Cytol, 1997,41:1341-1344

[9] Fukunaga M, Ushigome S. Small cell (oat cell) carcinoma of the breast. Pathol Int, 1998,48:744-748.

[10] Sebenik M, Nair SG, Hamati HF. Primary small cell anaplastic carcinoma of the breast diagnosed by fine needle aspiration cytology: a case report. Acta Cytol, 1998,42:1199-1203. patient, tumor cells of the SCC component were negative for ER, PR, and HER2. In addition, the high Ki67 index and the presence of metastases in 4 axillary lymph nodes may result in a high risk of disease relapse and metastasis. Thus, after her systemic and individual treatments, a rigorous clinical monitoring of disease relapse and metastasis is necessary.

\section{Conclusions}

In summary, primary SCC of the breast is a new challenge. Due to the rarity of cases, no standard treatment exists. According to previous reports, earlier detection and multidisciplinary therapies may be relevant to improved prognosis. Further studies with more cases will enhance our understanding of the clinicopathologic characteristics of this tumor and may result in the development of new therapeutic modalities, thus improving the outcome of these patients.

Received: 2012-01-13; revised: 2012-03-04; accepted: 2012-03-14.

[11] Samli B, Celik S, Evrensel T, et al. Primary neuroendocrine small cell carcinoma of the breast. Arch Pathol Lab Med, 2000, 124:296-298

[12] Yamasaki T, Shimazaki H, Aida S, et al. Primary small cell (oat cell) carcinoma of the breast: report of a case and review of the literature. Pathol Int, 2000,50:914-918.

[13] Shin SJ, De Lellis RA, Ying L, et al. Small cell carcinoma of the breast: a clinicopathologic and immunohistochemical study of nine patients. Am J Surg Pathol, 2000,24:1231-1238

[14] Salmo EN, Connolly CE. Primary small cell carcinomas of the breast: report of a case and review of the literature. Histopathology, 2001,38:277-278.

[15] Hoang MP, Maitra A, Gazdar AF, et al. Primary mammary small-cell carcinoma: a molecular analysis of 2 cases. Hum Pathol, 2001,32:753-757

[16] Sridhar P, Matey $P$ and Aluwihare N. Primary carcinoma of breast with small-cell differentiation. Breast, 2004,13:149-151.

[17] Jochems L, Tjalma WA. Primary small cell neuroendocrine tumour of the breast. Eur J Obstet Gynecol Reprod Biol, 2004,115:231-233.

[18] Yamamoto J, Ohshima K, Nabeshima K, et al. Comparative study of primary mammary small cell carcinoma, carcinoma with endocrine features and invasive ductal carcinoma. Oncol Rep, 2004,11:825-831.

[19] Bergman S, Hoda SA, Geisinger KR, et al. E-cadherinnegative primary small cell carcinoma of the breast. Report of a case and review of the literature. Am J Clin Pathol, 2004, 121:117-121.

[20] Mariscal A, Balliu E, Diaz R, et al. Primary oat cell carcinoma of the breast: imaging features. AJR Am J Roentgenol, 2004, 183: $1169-1171$. 
[21] Bigotti G, Coli A, Butti A, et al. Primary small cell neuroendocrine carcinoma of the breast. J Exp Clin Cancer Res, 2004,23:691-696.

[22] Adegbola T, Connolly CE, Mortimer G. Small cell neuroendocrine carcinoma of the breast: a report of three cases and review of the literature. J Clin Pathol, 2005,58:775778.

[23] Cabibi D, Cipolla C, Maria Florena A, et al. Solid variant of mammary 'adenoid cystic carcinoma with basaloid features' merging with 'small cell carcinoma'. Pathol Res Pract, 2005, 201:705-711.

[24] Stein ME, Gershuny A, Abdach L, et al. Primary small-cell carcinoma of the breast. Clin Oncol (R Coll Radiol), 2005,17: 201-202.

[25] Salman WD, Harrison JA, Howat AJ. Small-cell neuroendocrine carcinoma of the breast. J Clin Pathol, 2006,59:888.

[26] Haider K, Shahid RK, Finch D, et al. Extrapulmonary small cell cancer: a Canadian province's experience. Cancer, 2006,107: 2262-2269

[27] Kitakata $H$, Yasumoto $K$, Sudo $Y$, et al. A case of primary small cell carcinoma of the breast. Breast Cancer, 2007,14: 414-419.

[28] Kinoshita S, Hirano A, Komine K, et al. Primary small-cell neuroendocrine carcinoma of the breast: report of a case. Surg Today, 2008,38:734-738

[29] Sadanaga N, Okada S, Shiotani S, et al. Clinical characteristics of small cell carcinoma of the breast. Oncol Rep, 2008,19: 981-985.

[30] Yamaguchi R, Tanaka M, Otsuka H, et al. Neuroendocrine small cell carcinoma of the breast: report of a case. Med Mol Morphol, 2009,42:58-61.

[31] Hojo T, Kinoshita T, Shien T, et al. Primary small cell carcinoma of the breast. Breast Cancer, 2009,16:68-71.

[32] Ersahin C, Bandyopadhyay S, Bhargava R. Thyroid transcription factor-1 and "basal marker"-expressing small cell carcinoma of the breast. Int J Surg Pathol, 2009,17:368-372.

[33] Rineer J, Choi K, Sanmugarajah J. Small cell carcinoma of the breast. J Natl Med Assoc, 2009,101:1061-1064.

[34] Quirós Rivero J, Muñoz García JL, Cabrera Rodríguez JJ, et al. Extrapulmonary small cell carcinoma in breast and prostate. Clin Transl Oncol, 2009,11:698-700

[35] Haji AG, Sharma S, Vijaykumar DK, et al. Primary mammary small-cell carcinoma: a case report and review of the literature. Indian J Med Paediatr Oncol, 2009,30:31-34.

[36] Christie M, Chin-Lenn L, Watts MM, et al. Primary small cell carcinoma of the breast with TTF-1 and neuroendocrine marker expressing carcinoma in situ. Int J Clin Exp Pathol, 2010,3: $629-633$.

[37] Nicoletti S, Papi M, Drudi F, et al. Small cell neuroendocrine tumor of the breast in a 40 year-old woman: a case report. $J$ Med Case Reports, 2010,4:201.

[38] Kanat O, Kilickap S, Korkmaz T, et al. Primary small cell carcinoma of the breast: report of seven cases and review of the literature. Tumori, 2011,97:473-478.

[39] Rhodes A, Jasani B, Balaton AJ, et al. Frequency of oestrogen and progesterone receptor positivity by immunohistochemical analysis in 7016 breast carcinomas: correlation with patient age, assay sensitivity, threshold value, and mammographic screening. J Clin Pathol, 2000,53:688-696

[40] Press MF, Sauter G, Bernstein L, et al. Diagnostic evaluation of HER-2 as a molecular target: an assessment of accuracy and reproducibility of laboratory testing in large, prospective, randomized clinical trials. Clin Cancer Res, 2005,11:6598 6607

[41] Reck M, von Pawel J, Macha HN, et al. Randomized phase III trial of paclitaxel, etoposide, and carboplatin versus carboplatin, etoposide, and vincristine in patients with small-cell lung cancer. J Natl Cancer Inst, 2003,95:1118-1127. 